\title{
THE EFFECT OF VENESECTION ON ARTERIAL, SPINAL FLUID, AND VENOUS PRESSURES WITH ESPECIAL REFERENCE TO FAILURE OF THE LEFT AND RIGHT HEART
}

\author{
By HAROLD F. ROBERTSON AND FERDINAND FETTER \\ (From the Department of Medicine, University of Pennsylvania Medical School, Philadelphia)
}

(Received for publication September 13, 1934)

The correlation of venous, spinal fluid, and arterial pressure, before and after venesection, was studied in a series of twenty-two cases of failure of the left heart and thirteen cases of failure of the right heart. These cases were observed clinically with reference to the improvement after venesection alone, and also after venesection in combination with the removal of twenty cubic centimeters of spinal fluid.

The cases studied embraced various types of heart disease, including syphilitic, rheumatic, arteriosclerotic, and hypertensive.

\section{LITERATURE}

Eyster (1) attributed the value of venesection in cardiac congestion to the reduction of a high venous blood volume. He contended that by this procedure the right ventricle is relieved of an abnormal initial strain.

Harrison (2) in 1933 made the observation that cisternal pressure was lower in the upright than in the prone position, whereas venous pressure was higher in the upright than in the prone position. $\mathrm{He}$ found also that venous, spinal fluid, and cisternal pressures were all more elevated in patients with congestive heart failure than in patients with normal circulation.

Harrison (3) in 1934 concluded from his studies on cisternal pressure that the patient with cardiac congestion secures more relief from his orthopnea when in the sitting position because of lowered cisternal pressure, and in turn lessened embarrassment to the respiratory center. Spinal drainage, in most cases, was followed by a decrease in dyspnea.

Friedfeld and Fishberg (4) in their studies of "The Relation of the Cerebrospinal and Venous Pressures in Heart Failure" showed that an elevation of venous pressure in failure of the right heart was invariably associated with an elevation of the spinal fluid pressure. They noted that venous and cerebrospinal pressures were lowered as cardiac compensation was restored. An elevation of the spinal fluid pressure did not occur in failure of the left heart with a normal venous pressure.

Gravier (5) found no definite correlation between arterial and spinal fluid pressures.

Tzanck and Renault (6), Eyster and Middleton (7), and Clark (8), in clinical observations, found a close correlation between the deep venous (internal jugular) and spinal fluid pressures. These authors selected $200 \mathrm{~mm}$. of water as the critical level of venous pressure at which venesection is indicated.

Myerson and Loman (9), as well as Planques, Riser, and Sorel (10) found that arterial hypertension alone would not induce elevation of pressure in the cerebrospinal fluid, but that pressure of the latter was dependent upon the venous pressure.

Additional studies of venous and spinal fluid pressures not so directly related to our problem are listed in the bibliography (11-16).

\section{METHODS}

In failure of the right heart, we include those cases manifesting signs of venous congestion, dyspnea, cyanosis, ascending edema, effusion into the serous sacs, and enlargement of the liver.

In failure of the left heart, we include those cases with cardiac dyspnea without engorgement of the systemic veins and also cases of diminished vital capacity with cardiac asthma. The presence of protodiastolic gallop rhythm or accentuation of the pulmonic second sound inclined us to classify a case as in this group. There was usually, in these cases, no enlargement of the liver, no cyanosis, and no venous congestion.

Normal values for spinal fluid pressure taken between the $3 \mathrm{~d}$ and 4th lumbar vertebrae in the erect position we consider as varying from 150 to $400 \mathrm{~mm}$. of water.

Normal values for venous pressure at the level 
of the right auricle taken in the upright position we take as from 90 to $125 \mathrm{~mm}$. of water.

All readings were taken in the morning with the patients in the sitting position. The lumbar puncture needle was inserted in the usual manner, and a mercury manometer used to determine pressure. The mercury pressure was later calculated and expressed in millimeters of water. The ar- terial and venous pressure readings were then recorded, the former with a mercury sphygmomanometer, and the latter with an L glass tube of 7 $\mathrm{mm}$. diameter inserted into the antecubital vein. Care was exercised in reading the venous pressure to have the antecubital vein precisely at the level of the right auricle. When these three readings 'had been made, the patients were bled eight to

TABLE I

Arterial, cerebrospinal fuid, and venous pressures before and after venesection in failure of the right heart

\begin{tabular}{|c|c|c|c|c|c|c|c|c|}
\hline \multirow{2}{*}{$\begin{array}{l}\text { Patient } \\
\text { number }\end{array}$} & \multicolumn{2}{|c|}{ Arterial pressure } & \multicolumn{3}{|c|}{ Cerebrospinal fluid pressure } & \multicolumn{3}{|c|}{ Venous pressure } \\
\hline & Before & After & Before & After & Change & Before & After & Change \\
\hline 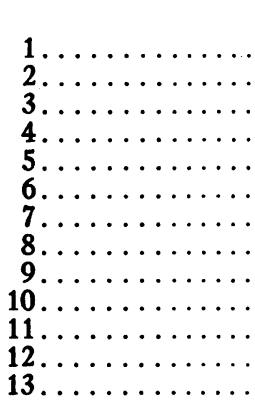 & $\begin{array}{c}\mathrm{mm} . \mathrm{Hg} \\
190 / 140 \\
60 / 10 \\
135 / 105 \\
146 / 118 \\
172 / 124 \\
190 / 130 \\
194 / 144 \\
220 / 160 \\
180 / 80 \\
180 / 70 \\
265 / 150 \\
180 / 140 \\
175 / 150\end{array}$ & $\begin{array}{c}m m . H g \\
175 / 125 \\
64 / 40 \\
140 / 100 \\
150 / 120 \\
162 / 110 \\
190 / 130 \\
194 / 144 \\
210 / 160 \\
165 / 70 \\
164 / 66 \\
265 / 145 \\
168 / 135 \\
175 / 140\end{array}$ & $\begin{array}{c}m m . \mathrm{H}_{2} \mathrm{O} \\
408 \\
354 \\
462 \\
408 \\
435 \\
394 \\
408 \\
408 \\
490 \\
435 \\
490 \\
435 \\
462\end{array}$ & $\begin{array}{c}m m_{.} \mathrm{H}_{2} \mathrm{O} \\
272 \\
272 \\
326 \\
354 \\
367 \\
394 \\
272 \\
204 \\
381 \\
326 \\
381 \\
408 \\
381\end{array}$ & $\begin{array}{r}m m . H_{2} \mathrm{O} \\
-136 \\
-82 \\
-136 \\
-\quad 54 \\
-68 \\
0 \\
-136 \\
-204 \\
-109 \\
-109 \\
-109 \\
-27 \\
-81\end{array}$ & $\begin{array}{c}m m . \mathrm{H}_{2} \mathrm{O} \\
245 \\
160 \\
220 \\
140 \\
195 \\
195 \\
200 \\
190 \\
265 \\
160 \\
220 \\
165 \\
230\end{array}$ & $\begin{array}{c}m m . \mathrm{H}_{2} \mathrm{O} \\
95 \\
135 \\
105 \\
50 \\
80 \\
120 \\
108 \\
130 \\
140 \\
100 \\
135 \\
140 \\
160\end{array}$ & $\begin{array}{c}m m . \mathrm{H}_{2} \mathrm{O} \\
-150 \\
-25 \\
-115 \\
-90 \\
-115 \\
-75 \\
-92 \\
-60 \\
-125 \\
-60 \\
-85 \\
-25 \\
-70\end{array}$ \\
\hline Average....... & & & 430 & 334 & -96 & 199 & 115 & -84 \\
\hline
\end{tabular}

TABLE II

Arterial, cerebrospinal fluid, and venous pressures before and after venesection in failure of the left heart

\begin{tabular}{|c|c|c|c|c|c|c|c|c|}
\hline \multirow{2}{*}{$\begin{array}{l}\text { Patient } \\
\text { number }\end{array}$} & \multicolumn{2}{|c|}{ Arterial pressure } & \multicolumn{3}{|c|}{ Cerebrospinal fluid pressure } & \multicolumn{3}{|c|}{ Venous pressure } \\
\hline & Before & After & Before & After & Change & Before & After & Change \\
\hline 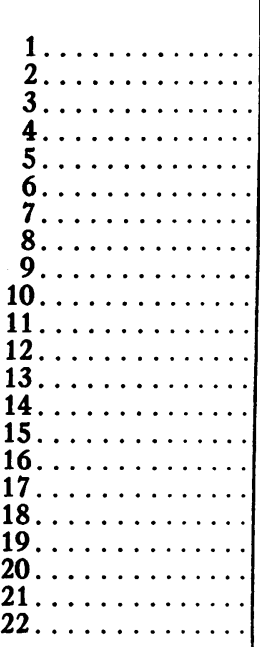 & $\begin{array}{l}m m . H g \\
202 / 114 \\
225 / 20 \\
198 / 102 \\
228 / 78 \\
150 / 20 \\
264 / 158 \\
198 / 156 \\
162 / 54 \\
182 / 112 \\
184 / 66 \\
180 / 100 \\
160 / 130 \\
280 / 160 \\
180 / 104 \\
250 / 170 \\
142 / 94 \\
230 / 125 \\
148 / 118 \\
120 / 80 \\
170 / 110 \\
138 / 90 \\
178 / 126\end{array}$ & $\begin{array}{l}\text { mm. Hg } \\
206 / 116 \\
180 / 50 \\
180 / 94 \\
204 / 75 \\
140 / 20 \\
225 / 150 \\
198 / 152 \\
160 / 72 \\
182 / 110 \\
120 / 98 \\
170 / 86 \\
160 / 130 \\
300 / 170 \\
150 / 112 \\
230 / 170 \\
142 / 94 \\
230 / 125 \\
138 / 110 \\
155 / 90 \\
170 / 110 \\
126 / 84 \\
162 / 104\end{array}$ & $\begin{array}{c}m m . H_{2} \mathrm{O} \\
490 \\
326 \\
299 \\
163 \\
476 \\
490 \\
326 \\
326 \\
299 \\
490 \\
354 \\
340 \\
326 \\
367 \\
408 \\
408 \\
462 \\
299 \\
354 \\
299 \\
326 \\
381\end{array}$ & $\begin{array}{c}m m . H_{2} \mathrm{O} \\
462 \\
326 \\
299 \\
136 \\
449 \\
422 \\
381 \\
326 \\
313 \\
408 \\
272 \\
340 \\
381 \\
367 \\
408 \\
408 \\
381 \\
272 \\
326 \\
299 \\
326 \\
326\end{array}$ & $\begin{array}{r}m m . H_{2} \mathrm{O} \\
-28 \\
0 \\
0 \\
-27 \\
-27 \\
-68 \\
+55 \\
0 \\
+14 \\
-82 \\
-82 \\
0 \\
+55 \\
0 \\
0 \\
0 \\
-81 \\
-27 \\
-28 \\
0 \\
0 \\
-\mathbf{5 5}\end{array}$ & $\begin{array}{c}m m . \mathrm{H}_{2} \mathrm{O} \\
90 \\
72 \\
110 \\
95 \\
70 \\
80 \\
70 \\
135 \\
100 \\
124 \\
85 \\
50 \\
30 \\
120 \\
90 \\
90 \\
125 \\
100 \\
70 \\
95 \\
135 \\
135\end{array}$ & $\begin{array}{c}m m . H_{2} \mathrm{O} \\
70 \\
58 \\
95 \\
85 \\
65 \\
80 \\
70 \\
90 \\
50 \\
95 \\
75 \\
80 \\
85 \\
110 \\
90 \\
90 \\
115 \\
80 \\
25 \\
90 \\
125 \\
118\end{array}$ & $\begin{array}{r}m m . H_{2} \mathrm{O} \\
-20 \\
-14 \\
-15 \\
-10 \\
-5 \\
0 \\
0 \\
-45 \\
-50 \\
-29 \\
-10 \\
+30 \\
+55 \\
-10 \\
0 \\
0 \\
-10 \\
-20 \\
-45 \\
-5 \\
-10 \\
-17\end{array}$ \\
\hline Average....... & & & 364 & 347 & -17 & 94 & 84 & -10 \\
\hline
\end{tabular}


twelve ounces. Subsequent to the venesection the same observations were again noted. Adequate time was allowed before each reading so that the patients' excitement would subside and not produce error. The sitting position was chosen because the readings were more accurate and no change of posture was necessary after the observations were begun.

We are indebted to Drs. William E. Robertson, David Riesman, Truman G. Schnabel, Robert G. Torrey, Henry D. Jump, and Howard D. Schaffer for the use of their patients in the Medical Wards of the Philadelphia General Hospital.

\section{OBSERVATIONS}

\section{Failure of the right heart}

A close relationship was found to exist between the spinal fluid and venous pressure in right heart failure. Both pressures were elevated in this type of congestive failure; the spinal fluid tension was always higher than the venous pressure, and a definite parallelism was observed. Arterial blood pressure had no relation whatever to the other two pressures. Following venesection of eight to twelve ounces, the venous and spinal fluid pressures consistently fell. Table I depicts the arterial, spinal fluid, and venous pressures before and after venesection. It is apparent from this table that spinal fluid pressure was consistently higher than venous pressure and that both were considerably above normal. The average spinal fluid pressure in millimeters of water before venesection was 430, and after venesection, 334. The average fall of lumbar spinal fluid pressure was 96. In only one of thirteen cases was no change noted. The average venous pressure before venesection was 199, and after venesection 115 . The average fall of venous pressure was 84 . The ratio of the mean spinal fluid pressure to mean venous pressure was not significantly altered by venesection (see Table III). Before venesection, it was 2.16; after venesection, 2.90. Venous pressure fell in all cases. The arterial pressure fell in six cases, rose in three, and remained approximately the same in four. Orthopnea was lessened in all patients immediately after venesection. In eight of the thirteen subjects, ten to twenty cubic centimeters of spinal fluid was withdrawn. We found that those patients who received both lum- bar drainage and venesection obtained the most rapid and permanent relief from their orthopnea.

\section{Failure of the left heart}

The close relation which existed between venous and spinal fluid pressures in right myocardial failure did not obtain in left heart failure. Table II shows the lower venous and spinal fluid pressures in the latter condition.

Inspection of Figure 3 reveals seven instances in which the spinal pressures are elevated above the normal values. This is attributed to the hydrostatic pressure effect, since these patients were elevated from a recumbent to a sitting position in order to determine the measurements. The remainder were initially in the upright position.

TABLE III

Ratios of mean spinal fluid and mean venous pressures before and after venesection

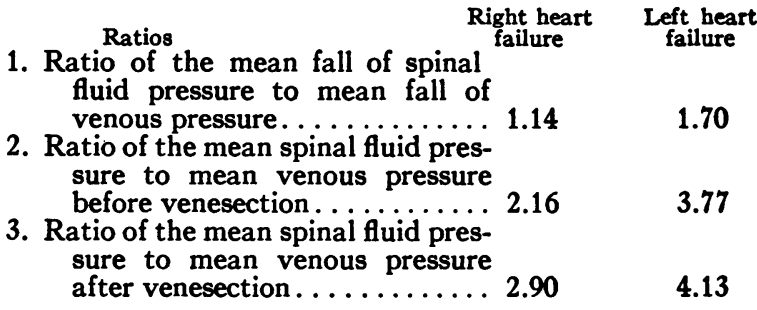

The average venous pressures before and after venesection in Table I are 199 and 115, whereas in Table II they are 94 and 84 . The average fall of venous pressure after bleeding was 84 in the right heart cases and 10 in the left. The average spinal fluid pressure in failure of the left heart was, before venesection, 364 , and after venesection, 347, with an average fall of 17 . The ratios of the mean values are given in Table III. Venous pressure fell in sixteen cases, rose in two, and remained constant in four. Arterial pressure again showed no relation to the spinal fluid and venous pressures. It rose in four cases, fell in twelve and remained the same in six. The presence of arterial hypertension did not indicate existing venous hypertension. The spinal fluid pressure fell in ten cases, rose in three, and remained unchanged in nine.

We feel justified in stating that venesection in hypertensive cardiovascular disease is not to be recommended unless there is elevation of the venous pressure, suggesting right ventricular failure. 


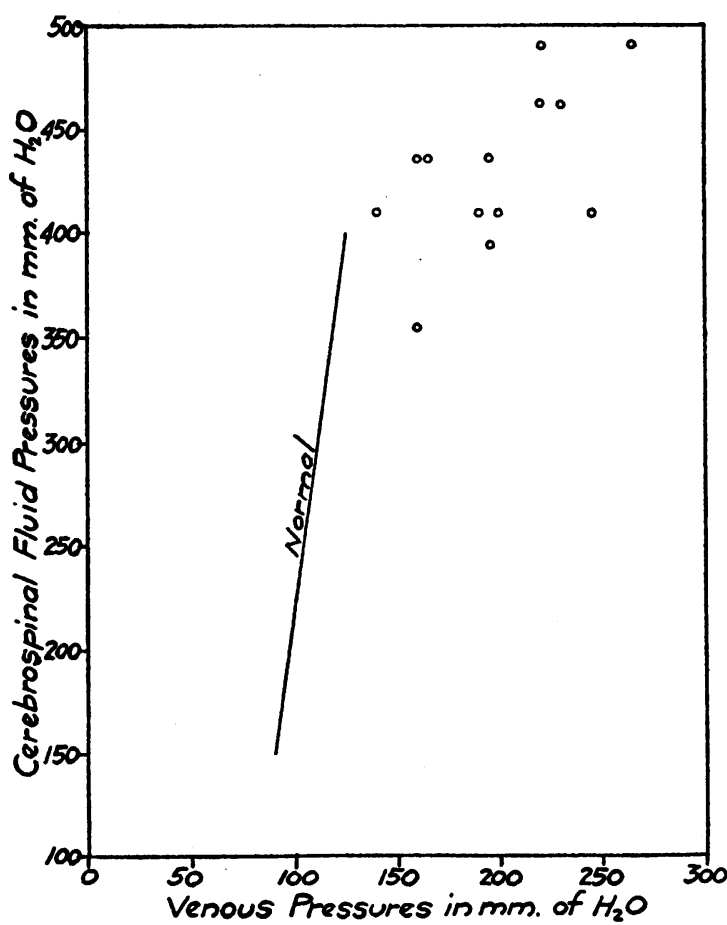

Fig. 1. Cerebrospinal Fluid Pressures and Venous Pressures in Right Heart Failure. (Before venesection.)

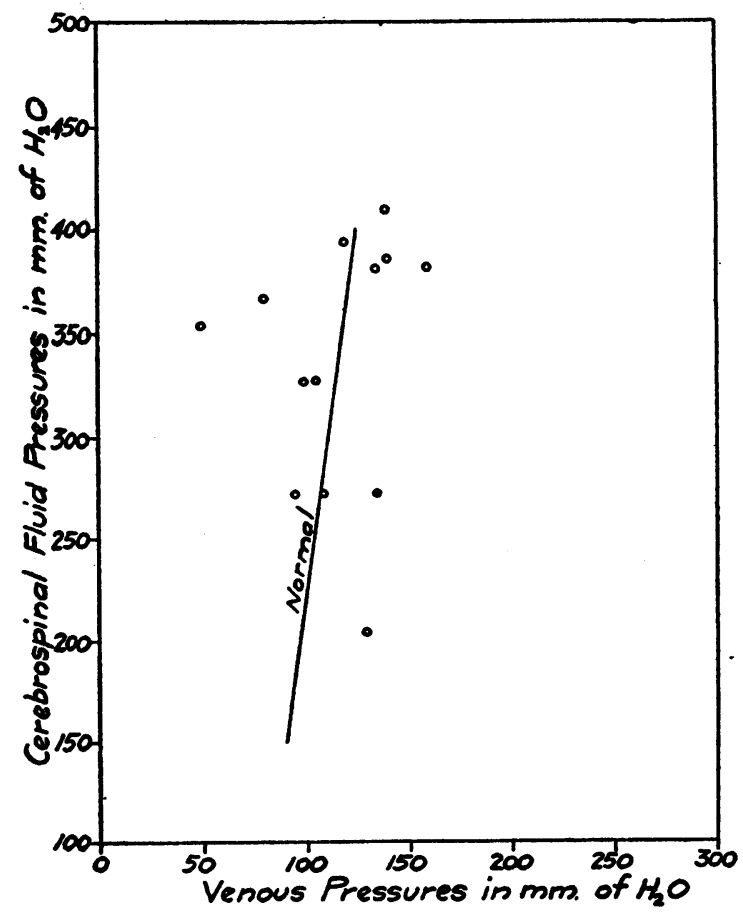

Fig. 2. Cerebrospinal Fluid Pressures and Venous Pressures in Right Heart Failure. (After venesection.)

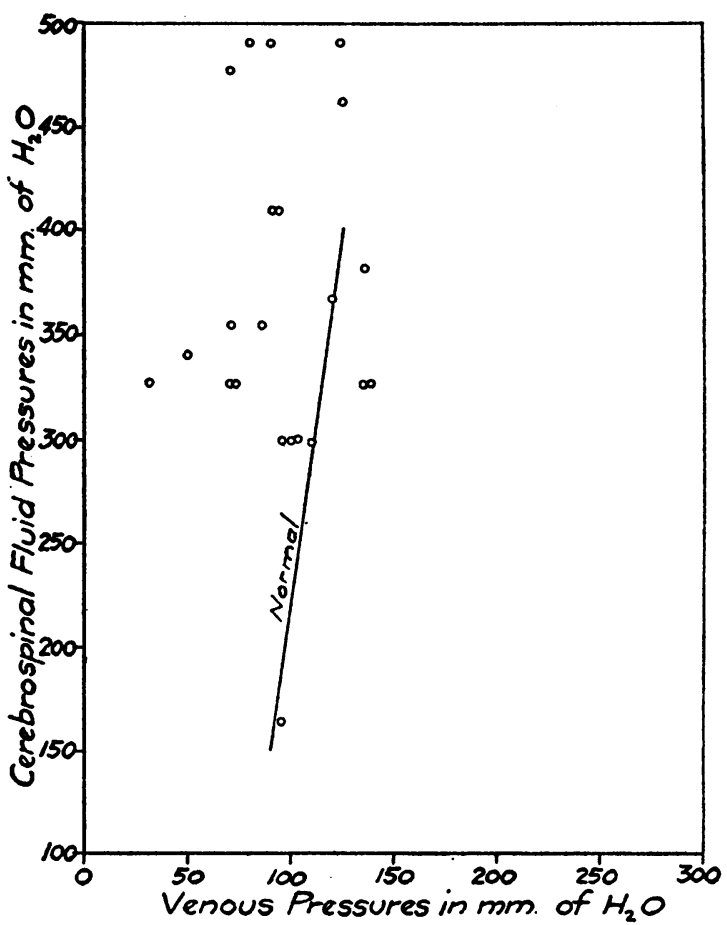

Fig. 3. Cerebrospinal Fluid Pressures and Venous Pressures in Left Heart Failure. (Before venesection.)

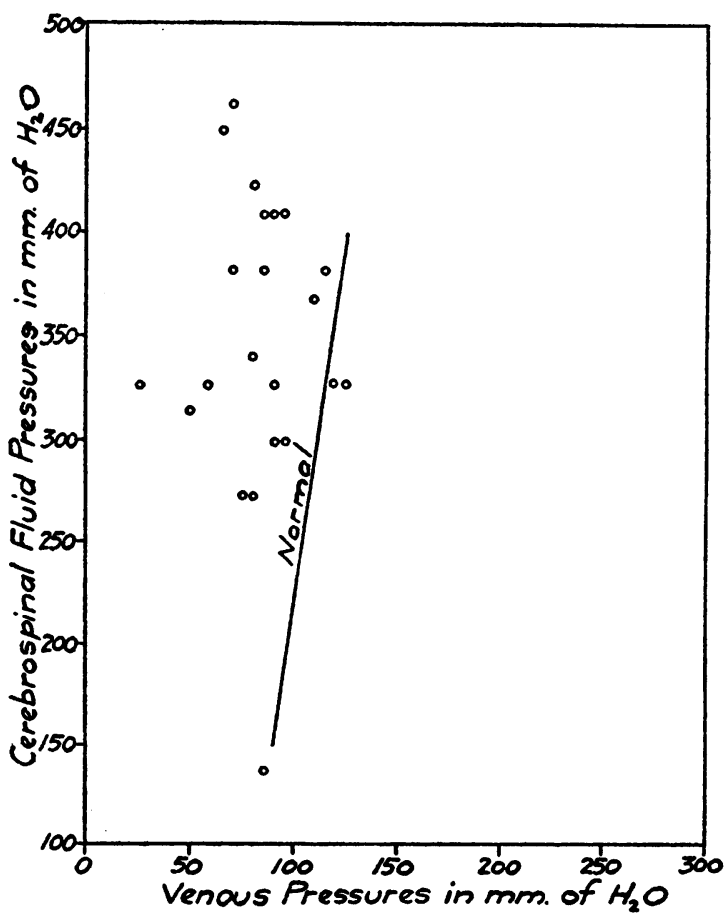

Fig. 4. Cerebrospinal Fluid Pressures and Venous Pressures in Left Heart Failure. (After venesection.) 


\section{DISCUSSION}

The foregoing observations show that venous and spinal fluid pressures are elevated in failure of the right heart, and that both fall after venesection. Inspection of Figures 1 and 2 reveals a tendency to parallel variation. Variation in the ratio between the two variables is shown by the divergences from a strictly linear distribution.

Since, in right heart failure, the demand upon the heart exceeds its physiologic response, it cannot convey into the pulmonary circulation the blood which comes to it from the venous circulation. Venous engorgement and stasis result consequently, especially upon failure of the right ventricle. It has long been known that phlebotomy relieves such venous and ventricular embarrassment.

We believe that if the pressure on the respiratory center is lessened by spinal fluid drainage the patient will obtain greater benefit than from venesection alone. With this in view, we combine the two procedures and find ample justification in the immediate clinical response.

Since, in failure of the left heart, the venous pressure is rarely or never elevated, treatment by combined venesection and lumbar drainage meets with little success. This method is found to be of no value in the hypertensive subject with a yielding of the left myocardium. Previous investigators have shown that arterial hypertension alone does not elevate spinal fluid pressure, but that the latter is dependent upon the venous tension. Our studies indicate no relation whatsoever between the arterial and the venous or spinal fluid pressures.

A thorough review of the literature revealed no similar study of the correlation between the three pressures. We think also that the combination of venesection with spinal drainage is an innovation in the treatment of failure of the right heart.

\section{SUM MARY}

A series of experiments was carried out to determine the relation of arterial, spinal fluid, and venous pressures before and after venesection.

It was found in right heart failure that venous and spinal fluid pressures were elevated and re- lated with respect to fall of pressures induced by venesection. The variation in the ratio between the two pressures is shown by the divergences from a linear distribution.

The spinal fluid pressure was elevated above normal in 32 per cent and 85 per cent of left and right heart failures, respectively. No correlation obtained between the arterial blood pressure and the venous or spinal fluid pressures in either right or left cardiac incompetence. The venous and spinal fluid pressures were uncorrelated in failure of the left heart. The spinal pressure was greater than the venous pressure in all of 140 observations made on 35 patients.

\section{BIBLIOGRAPHY}

1. Eyster, J. A. E., The clinical aspects of venous pressure. The Macmillan Company, New York, 1929.

2. Harrison, William G., Jr., The cisternal pressure in congestive heart failure and its bearing on orthopnea. J. Clin. Invest., 1933, 12, 1075.

3. Harrison, William G., Jr., Cerebrospinal fluid pressure and venous pressure in cardiac failure and the effect of spinal drainage in the treatment of cardiac decompensation. Arch. Int. Med., 1934, $53,782$.

4. Friedfeld, L., and Fishberg, A. M., The relation of the cerebrospinal and venous pressures in heart failure. J. Clin. Invest., 1934, 13, 495.

5. Gravier, L., La pression rachidienne dans l'hypertension artérielle. Marseille-méd., 1926, 63, 641.

6. Tzanck, A., and Renault, P., Des rapport entre la tension veineuse et la tension du liquide céphalorachidien. Compt. rend. Soc. de biol., 1927, 96, 157.

7. Eyster, J. A. E., and Middleton, W. S., Venous pressure as a guide to venesection in congestive heart failure. Am. J. M. Sc., 1927, 174, 486.

8. Clark, A. H., A study of the diagnostic and prognostic significance of venous pressure observations in cardiac disease. Arch. Int. Med., 1915, 16, 587.

9. Myerson, A., and Loman, J., Internal jugular venous pressure in man. Its relationship to cerebrospinal fluid and carotid arterial pressures. Arch. Neurol. and Psychiat., 1932, 27, 836.

10. Planques, Riser, and Sorel, R., Le Pression rachidienne chez les hypertendus artériels. Presse méd., 1933, 41, 513.

11. Claude, H., Targowla, A., and Lamache, A., Pression du liquide céphalorachidien et pression veineuse. Compt. rend. Soc. de biol., 1927, 96, 259.

12. Tzanck, A., and Renault, P., Les hypertensions rachidiennes d'origine mécanique (liquide céphalorachidien et masse sanguine). Bull. et mém. de la Soc. méd. d. hôp. de Paris, 1927, 51, 1441. 
13. Tzanck, A., and Renault, $P$., Tension rachidienne et pression veineuse profonde. Bull. et mém. de la Soc. méd. d. hôp. de Paris, 1927, 51, 1444.

14. Porot, M. A., Les fortes hypertension céphalorachidiennes d'origine veineuse. Leur latence. La discordance manométrique et clinique. Revue neurol., 1930, 1, 1173.
15. Lemaire, A., and Worms, R., Les variations de la tension du liquide céphalo-rachidien sous l'influence de la saignée. Progrès méd., 1932, 1, 1089.

16. Merklen, P., Kabaker, J., and Warter, J., Etude de la pression du liquide céphalo-rachidien et de la manoeuvre de Queckenstedt au cours de l'asystolie. Paris méd., 1933, 87, 405. 